\title{
A Rapid Primary Screening Method for Antitumor Using the Oomycete Pythium aphanidermatum
}

Suikinai Nobre Santos* and Itamar Soares Melo

Embrapa Environment, Brazilian Agricultural Research Corporation - EMBRAPA, Jaguariuna, São Paulo, Brazil

\begin{abstract}
Investigating bioactive components from microbial metabolites can provide potential source for drug discovery. There are a number of traditional antitumor compounds screening assays already described. In this study, we have developed an efficient method to search for antitumor compounds using the Oomycete Pythium aphanidermatum as model on agar plates for high throughtput screening. Antioomycete compounds showed cytotoxic effects in human cancer cells lines due to the possible similarity between the lipid cell membrane of the Pythium species and cancerous cells, suggesting the compounds act through similar mechanisms of inhibition. In this assay, it is possible to evaluate hundreds of samples, with results in few hours. The Pythium assay was shown to be sensitive for several chemical substances and allowed the detection and isolation of antitumor compounds from microorganisms. This bioassay was shown to be sensitive, rapid, simple and reliable for antitumor activity. It takes just few hours to evaluate the properties of the extracts.
\end{abstract}

Keywords: Antitumoral screening; Pythium aphanidermatum; Antifungal assay; Secondary metabolites

\section{Introduction}

Cancer is one of the leading causes of death. According to global cancer statistics released by the American Cancer Society [1], the total number of deaths from cancer in 2007 was 7.6 million and by 2050, 27 million new cancer cases and 17.5 million cancer deaths are projected to occur worldwide. Some antifungal substances can inhibit the growth of some tumor cells. They can be used as test model in cytotoxicity assays. Morphological deformations observed on mycelia of certain fungi induced by secondary metabolites have been known and were applied to screening for these compounds. This method detects morphological deformations of mycelia by culture broth of marine fungi, and has positive correlation with anticancer activity [2-4].

Pythium belongs to the Phylum Oomycota, classified as false fungus due to taxonomic and physiological factors. One of the factors to be considered is hyphal walls which are composed of $80-90 \%$ polysaccharides, mainly $\beta 1-6$ linked glucans and $\beta 1-3$ and $\beta 1-4$ [5]. It should be noted that Pythium spp. do not contain chitin or chitosan in the hyphal walls and cell membrane, but they do contain proteins and lipids at levels varying from $3-8 \%$ and from $1-3 \%$, respectively and sterols (cholesterol, $\beta$-sitosterol, etc.) which resemble cancer cells [6-8]. Studies suggest that cholesterol and cancer are closely associated, where the lipid bilayer membrane of cancer cells has a high concentration of cholesterols $[9,10]$. Rapidly proliferating tumor cells presumably require cholesterol for new membrane synthesis. Cholesterol accumulation may be a more general property of cancer, and it has been especially well correlated with breast and prostate cancer progression [11]. For many years, evidences have been accumulated indicating a possible central role of endogenous cholesterol in the pathobiology of cancer. Alterations in the synthesis, uptake, and membrane content of cholesterol have been observed in a variety of experimental tumor models as well as in human neoplasms [12-14]. It can be seen that the existence of similarity between the lipid physiological cell wall of Pythium species and cancerous cells suggest that the compounds act through similar mechanisms of inhibition.

Considering the need for effective methods to screen natural products for potential antitumor activity, the continuous demand for bioassays and the huge biodiversity for novel drugs in a quick way, the present study was undertaken to develop and be applied to the primary screening for antitumor compounds from microorganisms using the plant pathogenic fungus Pythium aphanidermatum. Here, we present an approach of utilizing bioassay-based highly sensitive antifungal activity, which is capable of detecting mycelia inhibition growth to a test compound with the advantages of being a rapid, quantitative, non invasive and in vitro method.

\section{Materials and Methods}

Pythium aphanidermatum was used as prescreen for discovery of antitumor and antifungal compounds. Extracts and fractions of 415 endophytic fungi isolated from Combretum leprosum, according to Santos et al. [13], were used in all bioassays. Fungal isolates were donated by the Culture Collection of Agricultural and Environmental Importance of the Brazilian Agricultural Research Corporation (EMBRAPA), Jaguariúna, São Paulo State, Brazil.

\section{Cultivation conditions, and the preparation of crude fungal extracts}

Each of the endophytic fungi was grown in 1 liter Erlenmeyer flasks containing $500 \mathrm{~mL}$ Czapek broth $\left(3 \% \mathrm{NaNO}_{3}, 2 \% \mathrm{~K}_{2} \mathrm{HPO}_{4}, 2 \%\right.$ $\mathrm{MgSO}_{4}: 7 \mathrm{H}_{2} \mathrm{O}, 1 \% \mathrm{KCl}, 30 \mathrm{mg}$ glucose, $1 \mathrm{~g}$ Bacto yeast extract, $3 \mathrm{mg}$ $\mathrm{FeSO}_{4} \cdot 7 \mathrm{H}_{2} \mathrm{O}$, HiMedia') and incubated at room temperature for 30 days under stationary conditions. Three pieces $\left(0.5 \times 0.5 \mathrm{~cm}^{2}\right)$ of mycelia agar plugs of 8 -days-old culture was used as inoculum. The broth culture was filtered to separate the filtrate and mycelia. The extraction of the secondary metabolites was performed with dichloromethane $(1: 1 \mathrm{w} / \mathrm{v})$. The solvent was then removed by flash evaporation at $45^{\circ} \mathrm{C}$. The extracts were stored in a freezer at $-20^{\circ} \mathrm{C}$, until the evaluation of the bioactivity.

\section{Antifungal activity with Pythium aphanidermatum as screening model}

Procedures for the antifungal assay against $P$. aphanidermatum were performed using the agar cup disc diffusion method with few

*Corresponding author: Suikinai Nobre Santos, Laboratory of Microbiology, EMBRAPA Environment (CNPMA), Rod. SP 340, Km 127, 5 CP 69, CEP: 13820 000 Jaguariúna, SP, Brazil, Tel: +551933112665; Fax: +551933112640; E-mail: Suikinai@gmail.com

Received August 27, 2016; Accepted September 12, 2016; Published September 17,2016

Citation: Santos SN, Melo IS (2016) A Rapid Primary Screening Method for Antitumor Using the Oomycete Pythium aphanidermatum. Nat Prod Chem Res 4: 241. doi: 10.4172/2329-6836.1000241

Copyright: (c) 2016 Santos SN, et al. This is an open-access article distributed under the terms of the Creative Commons Attribution License, which permits unrestricted use, distribution, and reproduction in any medium, provided the original author and source are credited. 
Citation: Santos SN, Melo IS (2016) A Rapid Primary Screening Method for Antitumor Using the Oomycete Pythium aphanidermatum. Nat Prod Chem Res 4: 241. doi: 10.4172/2329-6836.1000241

Page 2 of 4

adaptations [14], described below. Fungal discs from overnight cultures were placed into Petri dishes with potato dextrose agar (PDA) and incubated for $24 \mathrm{~h}$ at $28^{\circ} \mathrm{C}$. All extracts and fractions were dissolved in Dimethyl Sulphoxide P.A. (Sigma-Aldrich, Saint Louis) solvent, 5 $\mathrm{mm}$ filter paper discs (Whatman $\mathrm{n}^{\circ} 1$ ) were impregnated with $10 \mu \mathrm{L}$ of the extracts with $250 \mu \mathrm{g} \cdot \mathrm{mL}^{-1}$ of concentration. The plates were prepared according to the following intructions: an agar plug with plenty growth of $P$. aphanidermatum was positioned in the center of the plates. The paper disc was impregnated with the extracts and positioned equidistantly $2 \mathrm{~cm}$ of the center. All plates were incubated at $28^{\circ} \mathrm{C}$ for 17 hours, when the evaluation of the bioactivity was recorded. Combretastatin $\left(50 \mu \mathrm{g} \cdot \mathrm{mL}^{-1}\right)$ and Pirarubicin $\left(30 \mu \mathrm{g} \cdot \mathrm{mL}^{-1}\right)$ were used as control. All tests were performed in triplicate.

\section{Cytotoxicity assay}

Analysis of cytotoxic effects of the fractions were carried out against the following tumor cell lines: ECV304 (bladder carcinoma), B16F10 (mouse melanoma), J774 (histiocytic sarcoma), and k562 (Chronic myelogenous leukemia). Solution with different concentrations $\left(1.10^{4}\right.$ $\mu \mathrm{g} \cdot \mathrm{mL}^{-1}, 1.10^{3} \mu \mathrm{g} \cdot \mathrm{mL}^{-1} 1.10^{2} \mu \mathrm{g} \cdot \mathrm{mL}^{-1} 10 \mu \mathrm{g} \cdot \mathrm{mL}^{-1}, 1 \mu \mathrm{g} \cdot \mathrm{mL}^{-1}$ ) were obtained by diluting the extracts with RPMI1640 medium and dimethyl sulfoxide (9:1). All tumor cell lines used in the present study were obtained from the Oswaldo Cruz Foundation, Rio de Janeiro, Brazil. The colorimetric methodology for the respiratory route of mitochondria MTT (3-(4,5-dimethylthiazol-2-y1)-2,5- diphenyl tetrazolium bromide) was used, as describe by some authors [13,15].

All experiments were performed in quintuplicate. Commercial chemotherapeutic pirarubicin was considered as standard drug. The inhibition of cell growth by samples tested was calculated using the following formula: percentage of anticancer activity (Ac As/ Ac) $\times$ $100 \%$. Ac and as refer to the absorbance of control and the sample, respectively. The $\mathrm{IC}_{50}$ (i.e., the dose of extracts response by $50 \%$ relative to the control value), which are reported as geometric means accompanied by their respective $95 \%$ confidence limits. The $\mathrm{IC}_{50}$ value was determined by linear regression from individual experiments using GraphPad software (GraphPad software, San Diego, CA, USA) and was used for statistical analysis.

\section{Effect on the morphology of transformed tEnd. 1 cells}

To assess the effects of the compounds on the morphology of endothelial cells, we used tEnd.1 cells line, which is derived from the murine thymic (tEnd.1) endothelioma cells. Strains were grown in RPMI1640 containing 2mM L-glutamine, $10 \%$ fetal bovine serum and $100 \mu \mathrm{gmL} \mathrm{m}^{-1}$ streptomycin $\left(37^{\circ} \mathrm{C}, 5 \% \mathrm{CO}_{2}\right)$. Exponentially growing tEnd. 1 cells were plated onto 24 well plates at $2.5 \times 10^{4} / 500 \mu \mathrm{L} /$ well. Twenty-four hour after plating, the medium was aspirated, and $300 \mu \mathrm{L}$ of medium containing the test compound solubilized in RPMI1640 and DMSO (1\%) was added to the well containing the wells (in triplicate) in $1.10^{3} \mu \mathrm{g} \cdot \mathrm{mL}^{-1}$ dilutions and incubated for $2 \mathrm{~h}$ at $37^{\circ} \mathrm{C}$ and $5 \% \mathrm{CO}_{2}$ [13]. After the $2 \mathrm{~h}$ incubation period, digital photographs were taken of representative center areas of each well at a magnification of $100 \mathrm{X}$. Pirarubicin and combretastatin CA4 were included in the experiments as chemotherapic standards.

\section{Results and Discussion}

In this investigation, we have efficiently proved the use of the plant pathogenic fungus Pythium aphanidermatum is a reliable and reproducible procedure for rapidly testing great quantities of samples. In this assay, we can evaluate hundreds of samples, being possible to have all results in this period of time as the fungal growth reaches the whole plate in 24 hours. Dichloromethane extracts of 415 endophytic fungal strains were tested against $P$. aphanidermatum and $28 \%$ of all dichloromethane extracts showed strong inhibition $(3+)$ followed by medium inhibition of mycelial growth $(2+)$ and moderate $(+)$ as showed in Figure 1.

To evaluate the antitumor potential and verify our assertions, fractions from partitioning extract with the highest inhibitory activity

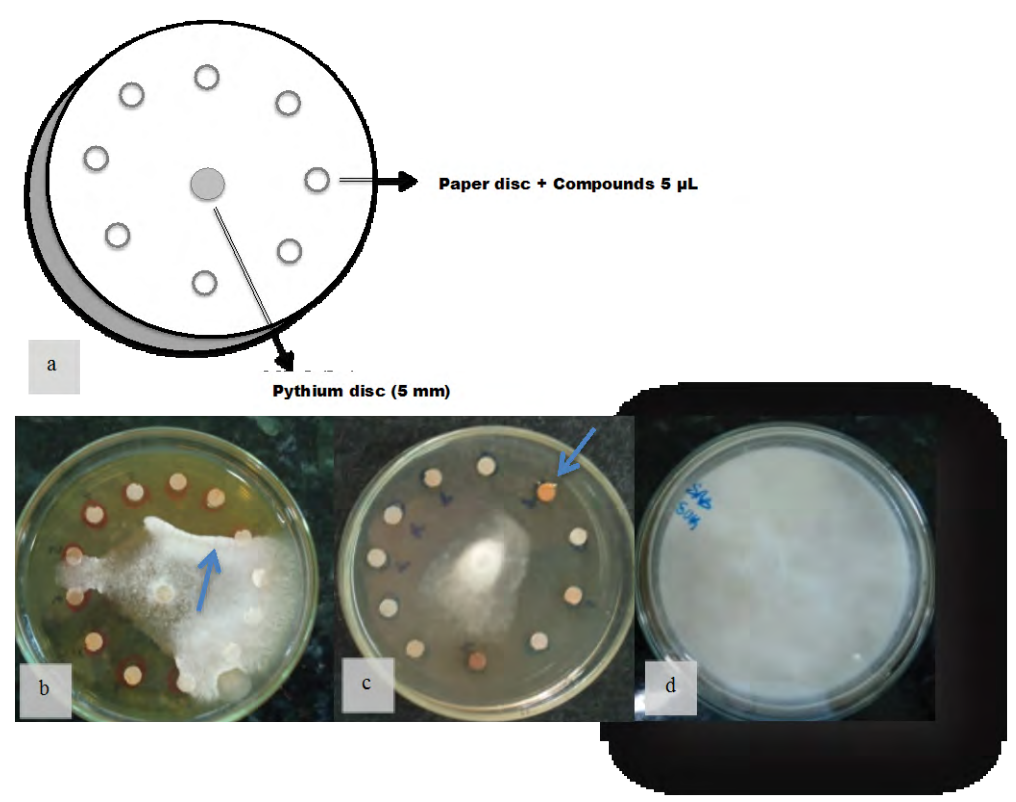

Figure 1: Schematic model of the disk diffusion test Kirby-Bauer adapted to Anti-oomycete activity against Pythium aphanidermatum of the endophytic fungi extracts; a) the center of the plate a plug with mycelium of Pythium grown 24 hours $(5 \mathrm{~cm})$, impregnated paper disc with extracts prepared test $2 \mathrm{~cm}$ from the center uniformly. The picture b) and c) are the results of Anti-oomycety activity with inhibitions of the Pythium mycelium growth, as indicated in arrows and as compared as control plate (d) normal growth of Pythium aphanidermantum. 
Citation: Santos SN, Melo IS (2016) A Rapid Primary Screening Method for Antitumor Using the Oomycete Pythium aphanidermatum. Nat Prod Chem Res 4: 241. doi: 10.4172/2329-6836.1000241

Page 3 of 4

were subjected to bioguided assay for cytotoxicity. The FR05 sample showed significant cytotoxic effects against lines causing no solids tumors: J774 with $\mathrm{IC}_{50}$ of 0.80 and $\mathrm{K} 562$ with $\mathrm{IC}_{50}$ of 1.47 , Figure 2. Among the solid tumors, ECV304 showed inhibition with $\mathrm{IC}_{50}$ of 2.97 and $\mathrm{B} 16 \mathrm{~F} 10$ with $\mathrm{IC}_{50}$ of 5 . The fraction FR05 as well as drug patterns showed cytotoxic activity in these cells, and the pirarubicin showed the highest cytotoxicity followed by pirarubicin and combretastatin A4. The fraction Fr03 and Fr08 did not show antitumor activity, in the same way, absence of inhibition of $P$. aphanidermatum.
Most often strategies have been developed to target tumor vasculature, combining therapies with cytotoxic agents that prevents the formation of new vessels in tumors as the anti-angiogenesis approach. Compounds that selectively target the preexisting tumor vasculature and cause damage to the endothelial cell layer are able stop the tumor blood supply [16]. However, in spite of this, we evaluated the action of the fractions in the transformation of tEnd.1 cells morphology, with observation of star-shaped cells and adhered to the bottom of plates, Figure 3. When treated with CA4, morphological changes were also observed leading to complete loss of adhesion, possibly preventing
A

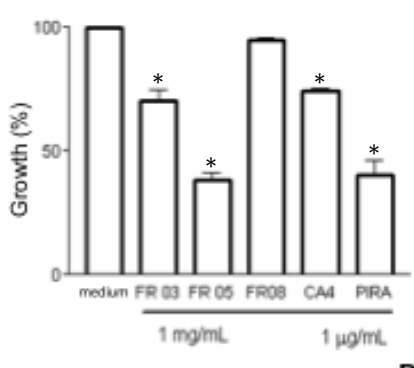

B ECV 304

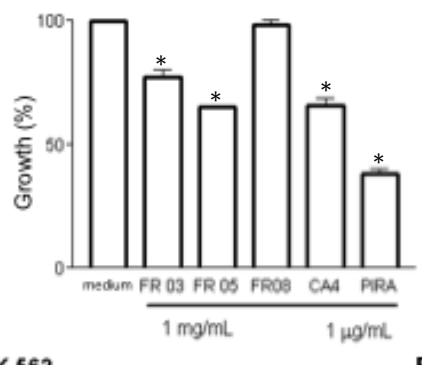

C $\mathbf{J 7 7 4}$

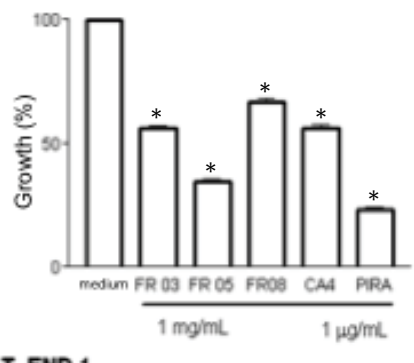

D $\mathrm{K} 562$

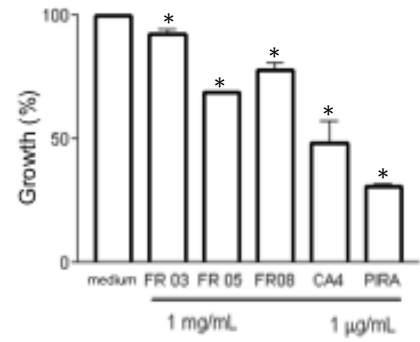

E T. END 1

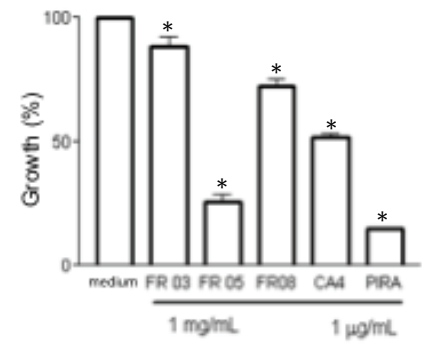

Figure 2: Cell growth measurements using conventional cytotoxicity MTT assay: Graphs showed the results of cytotoxicity of the fractions (Fr03, Fr05 and Fr08) in cancer human cells: A) B16F10 (Mouse melanoma), B) ECV304 (Bladder carcinoma), C) J774 (Histiocytic sarcoma), D) K562 (Chronic myelogenous leukemia) and E) T.end 1 (Endothelial cells) at a concentration $1 \mathrm{mg} \mathrm{mL}^{-1}$ each fraction. The standard drugs used was Combretastatin (CA4) and Pirarubicin (PIRA) at concentration of $1 \mu \mathrm{g} \cdot \mathrm{mL}^{-1}$; Negative control was solution of medium RPMI and Tween ( $20 \%$, Sigma, Saint. Lous) (t-test, * $\mathrm{P}<0.05, \mathrm{n}=5 \mathrm{compared}$ to the control, medium).

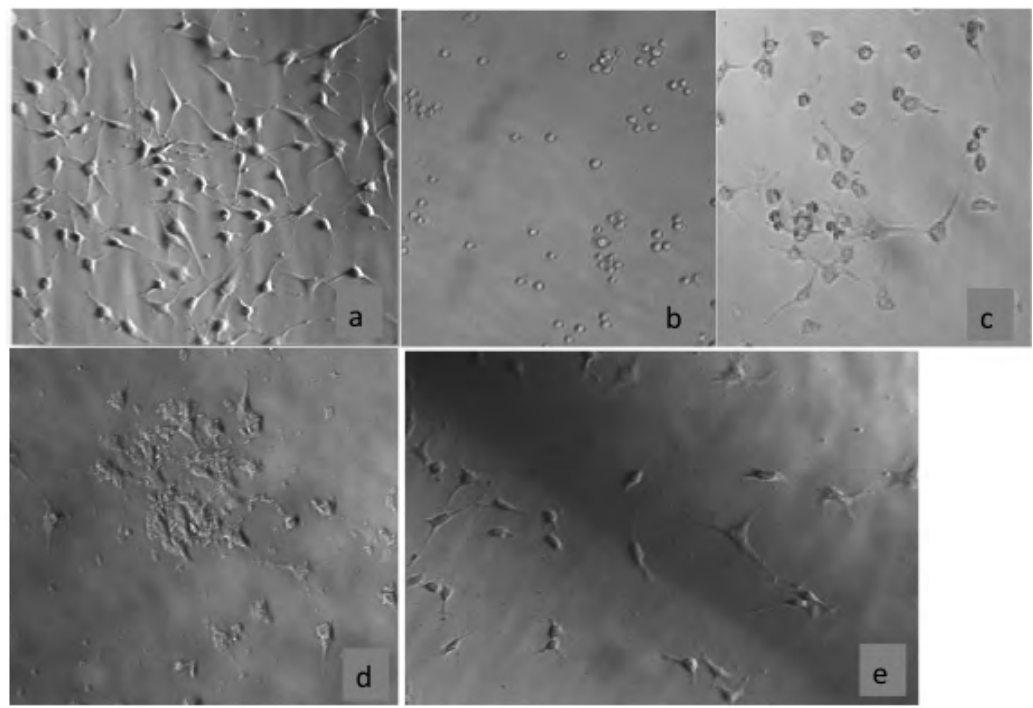

Figure 3: Image-based cell morphological effects. Endothelial cells (tEnd.1) were treated with Fr05 and incubated for $2 \mathrm{~h}$ at $1.10^{3} \mu \mathrm{g} \cdot \mathrm{mL}^{-1} \mathrm{concentration}$. Representative photographs shown were recorded at a magnification of $360 \mathrm{X}$ a) culture media with cells tEnd.1; b) Combretastatin CA4 treatment; c) Pirarrubicin treatment; d) and e) effect of the fraction Fr05 from secundary metabolites from microorganisms (Zess: Axiovert inverted). 
the formation of future blood vessels in tumors. The pirarubicin and fraction test (Fr05) caused rounding of the cells and decreased the starry shape, possibly preventing the formation of tumor vessels, but in different proportions to CA4. Tumor neovascularization occurs primarily through the sprouting of established vessels, a process that includes the migration of endothelial cells (EC) out of an existing vessel into the surrounding extracellular matrix (ECM) and their organization and morphogenesis into tube-like structures. Agents that interfere in these events potentially have antiangiogenic activity $[16,17]$.

In this investigation, we have efficiently proved that the use of the plant pathogenic fungus is a reliable and reproducible procedure for rapidly testing great quantities of samples. In this assay, we could evaluate 415 samples, being possible to have all results in this period of time as the fungal growth reaches the whole plate in 24 hours.

Therefore, the results showed a positive correlation between the antifungal activity and antitumor tests using $P$. aphanidermatum model line as a prescreening agent for targeting potential antitumor compounds.

\section{Acknowledgements}

The authors thank the Brazilian agencies FAPESP (Process 2013/16037-0) for fellowships, Dr. Fausto K Ferraris and Oswaldo Cruz Foundation with support for cytotoxicity bioassay.

\section{Conflict of Interest}

The authors have declared that there is no conflict of interest.

\section{References}

1. American Cancer Society (2007) Global cancer facts and figures 2007. American Cancer Society, Atlanta, USA.

2. Gunji S, Arima K, Beppu T (1983) Screening of antifungal antibiotics according to activities inducing morphological abnormalities. Agric Biol Che 47: 20612069.

3. Beppu T (1993) Morphological abnormalities of eukaryotic cell induced by microbial metabolites as indices to direct nobel physiological activities. Prot Nuc Ac Enz 38: 1639-1646.
4. Kobayashi H, Namikoshi M, Yoshimoto T, Yokochi T (1996) A screening method for antimitotic and antifungal substances using conidia of Pyricularia oryzae, modification and application to tropical marine fungi. J Antib 49: 873-879.

5. Postma J, Stevens LH, Weigers GL, Davelaar E, Nijhuls EH (2009) Biological control of Pythium aphanidermatum in cucumber with a combined application of Lysobacter enzymogenes strain 3.1T8 and chitosan. Bio Cont 48: 301-309.

6. Pystina KA (1974) Effect of sterols and vegetable oils on growth and sexual reproduction of fungi of the genus. Pyt Mik Fitop 7: 493-498.

7. Nzungize JR, Lyumugabe F, Busogoro JP, Baudoin JP (2012) Pythium root rot of common bean: biology and control methods. A review. Biot Agro Soc Envir 16: $405-413$

8. Li YC, Park MJ, Ye SK, Kim CW, Kim YN (2006) Elevated Levels of CholesterolRich Lipid Rafts in Cancer Cells Are Correlated with Apoptosis Sensitivity Induced by Cholesterol-Depleting Agents. The Amer J of Path 168: 1107-1118.

9. Van der Paal J, Neyts EC, Verlack CCW, Bogaerts B (2016) A Effect of lipid peroxidation on membrane permeability of cancer and normal cells subjected to oxidative stress. Chem Sci 7: 489-498.

10. Natter K, Kohlwein SD (2013) Yeast and cancer cells - common principles in lipid metabolism. Biochimica et Biophysica Acta 1831: 314-326.

11. Dessi S, Batetta B, Pulisci D, Spano O, Anchisi C, et al. (1994) Cholestero content in tumor tissues is inversely associated with high-density lipoprotein cholesterol in serum in patients with gastrointestinal cancer. Cancer 73: 253-258.

12. Santos SN, Ferraris KF, Souza AO, Henriques MG, Melo IS (2012) Endophytic fungi from Combretum leprosum with potential anticancer and antifungal activity. Symb 58: 109-117.

13. Nancy T, Dupeyre G, Chabot GG, Seguin J, Tillequin F, et al. (2008) Synthesis and biological evaluation of new disubstituted analogues of 6-methoxy-3-( $3^{\prime}, 4^{\prime}, 5^{\prime},-$ trimethox- ybenzol)-1H-indole (BPROL075), as potential antivascular agents. Bioorg Med Chem 16: 7494-7503.

14. Twiddy AL, Leon CG, Wasan KM (2011) Cholesterol as a potential target for castration "A Comparison of Cholesterol Uptake and Storage in Inflammatory and Noninflammatory Breast Cancer Cells". J Bre Canc 3: 423-437.

15. Bauer AW, Kirby WM, Sherris JC, Turck M (1966) Antibiotic susceptibility testing by a standardized single disk method. Am J Clin Pathol 45: 493-496.

16. Mosmann T (1983) Rapid colorimetric assay for cellular growth and survival application to proliferation and cytotoxicity assays. J Imm Met 65: 55-63.

17. Tozer GM, Kanthou C, Baguley BC (2005) Disrupting tumour blood vessels Nat Rev Canc 5: 423-435. 